\title{
Current Developments of Energy Scavenging, Converting and Storing in WSNs
}

\author{
A.A. Bhaskar \\ Assistant Professor \\ Department of E\&CE \\ SPSU, Udaipur
}

\author{
R. Champawat \\ Research Scholar \\ Department of E\&CE \\ SPSU, Udaipur
}

\author{
S.A. Bhaskar \\ Research Scholar \\ Department of Electronics \\ SU, Rajkot
}

\begin{abstract}
Wireless sensor networks (WSNs) design requires multidisciplinary approach in the field of wireless communication, embedded systems, networking, digital signal processing, hardware and software engineering. Major factors to influence the WSNs design are hardware and software constraints, scalability, cost, transmission media, network topology and power consumption etc. Most of WSN nodes are battery powered. With the limited capacity of batteries to power WSN nodes, need of energy harvester or scavenger is required to harvest or scavenge energy from the environment to improve the life-time of the sensor node. The harvested or scavenged energy is converted by power converters to recharge the sensor nodes or for the storage devices. This paper gives current developments of energy harvesting technologies, power converters and storage devices proposed by various researchers in WSNs along with some open research problems.
\end{abstract}

\section{Keywords}

Energy Harvesting, Power Management System, Wireless Sensor Networks, Power Convertors, Energy Storage Devices.

\section{INTRODUCTION}

Scavenging energy from the environment is an enviable and growingly important means in several emerging applications of embedded systems such as wireless sensor networks. The process by which energy is derived from surrounding sources like vibration energy, light energy, thermal energy, wireless energy, wind energy, chemical energy, acoustic energy, etc. is captured and stored in order to power such systems like wireless sensor networks is termed as Energy harvesting or scavenging [1].

Sensor nodes are commonly power driven by battery, but when the number of nodes and size is augmented the replacement of washed-out batteries is quite complicated and profligate. In many researches upper energy-density batteries and supercapacitors are exploited, but the accessible energy amount is still cruelly limits the system's natural life. Consequently, there is an obvious impose to explore novel alternatives to power driven sensor nodes. As a result Sensor networks can accomplish much larger run-times, years not months, with potentially lesser cost and weight by harvesting energy from their local environment [2].

For power driven wireless sensor nodes there are three main technology categories: energy harvesting or scavenging, energy converting and energy storage. This paper reviews the state-of-the art technology in all of these fields. These include energy scavenging sources like vibration energy, light energy, thermal energy, wireless energy, wind energy, chemical energy, acoustic energy etc., energy converters such as DCDC converters, DC-AC converters, AC-DC rectifiers and energy storage utilizing batteries and supercapacitor.

According to the magnitude of output power and impedance, the harvested energy can be used directly or stored into energy storage device There are numerous technologies rising on the market that aspire at converting these ambient energy sources into useable electrical energy. One can exploit the existing energy in the environment to produce electricity at any given locality to deliver power for wireless sensor nodes.

There is necessity to merge the design and fabrication with appropriate interface circuit for the objective of realizing selfpower of wireless sensor nodes. Each has its own unique output characteristics (open circuit voltage, short circuit current and maximum power operating point) [3]. It would be desirable to develop a universal means of converting the electrical energy derived from energy harvesters, that are both apt in size and cost, and storing it in a form that is suitable for powering electronic devices.

This paper is a review of various energy scavenging sources, power converters and energy storage systems. Collectively, this type of device could be used in concurrence with energy harvesting technologies to provide an attractive solution to the problem of powering wireless sensor network nodes.

\section{ENERGY SCAVENGING TECHNIQUES}

Figure 1 shows the present energy harvesting techniques used in different WSN applications. This mainly comprises of Vibration, Light, Thermo, Wireless, Wind, Biochemical, and Acoustic energy sources. The comparison of various energy harvesting techniques in terms of power density is given in Table 1. Current developments in energy harvesting are discussed below in this section.

\subsection{Vibrtion}

Vibration energy can be harvested from different means and by converting this energy into electricity. Vibration energy harvesting is separated in three categories: Electromagnetic, Electrostatics and Piezoelectric [4]. 


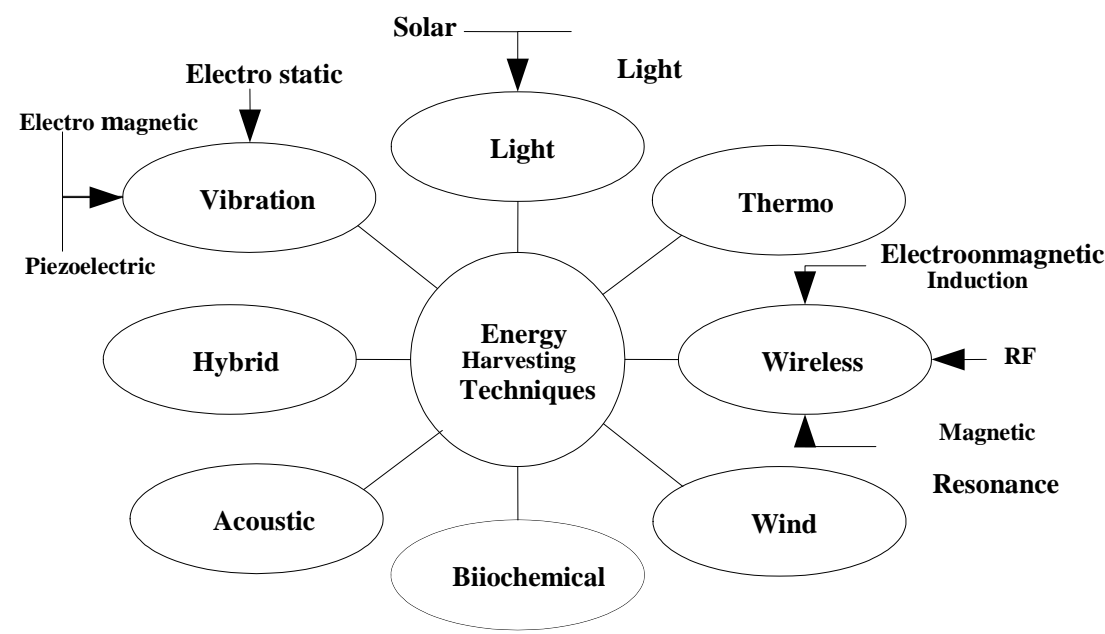

Fig 1: Energy Harvesting Techniques used in WSN applications.

Table 1. Comparison of various energy harvesting Techniques

\begin{tabular}{|c|c|c|}
\hline \multicolumn{2}{|c|}{ Energy Harvesting Techniques for WSN } & Power Density \\
\hline \multirow{3}{*}{ Vibration } & Pizoelectric & $330 \mu \mathrm{W} / \mathrm{Cm}^{3}$ \\
\hline & Electrostatic & $50-100 \mu \mathrm{W} / \mathrm{Cm}^{3}$ \\
\hline & Electromagnetic & $\begin{array}{c}184-306 \mu \mathrm{W} / \\
\mathrm{Cm}^{3}\end{array}$ \\
\hline \multirow{2}{*}{ Solar(Photovoltaic) } & Indoor & $10-100 \mu \mathrm{W} / \mathrm{Cm}^{2}$ \\
\hline & Outdoor (bright day) & $15 \mathrm{~mW} / \mathrm{Cm}^{3}$ \\
\hline \multirow{2}{*}{ Thermal } & Thermoelectric & $40 \mu \mathrm{W} / \mathrm{Cm}^{3}$ \\
\hline & $\begin{array}{c}\text { Pyroelectric(at } \\
\left.8.5^{\circ} \mathrm{C} / \mathrm{s}\right)\end{array}$ & $8.64 \mu \mathrm{W} / \mathrm{Cm}^{2}$ \\
\hline Wireless & RF Energy & $\begin{array}{c}0.01-0.1 \mu \mathrm{W} / \\
\mathrm{Cm}^{2}\end{array}$ \\
\hline Wind & At $5 \mathrm{~m} / \mathrm{s}$ & $16.2 \mu \mathrm{W} / \mathrm{Cm}^{2}$ \\
\hline \multirow{2}{*}{ Acoustic } & At $100 \mathrm{db}$ & $0.96 \mu \mathrm{W} / \mathrm{Cm}^{3}$ \\
\hline & At $75 \mathrm{db}$ & $3 \mathrm{nW} / \mathrm{Cm}^{3}$ \\
\hline
\end{tabular}

\subsubsection{Electromagnetic}

Electromagnetic transduction is based on the generation of voltage resulting from a relative motion between a coil and a magnet [5]. The electromagnetic vibration energy harvesters can be simply packaged to reduce the risk of corrosion and eliminate the temperature limit. Many researchers focus on electromagnetic vibration energy harvesters ranging from micro electro mechanical (MEM) devices to larger scale devices with the dimensions of order of a few centimeters. It has been shown that an optimized device is capable of converting up to $30 \%$ of the total energy supplied into useful electrical energy [6]. There are four available magnets: ceramic, Alnico, SmCo, and $\mathrm{NdFeB}$, among these, $\mathrm{NdFeB}$ has the largest magnetic field intensity, high coercive force, and no demagnetization due to the vibration of generator [7].
Rahimi et al. proposed a vibration-based electromagnetic energy harvester system powering a $1.5 \mathrm{~V}, 15 \mu \mathrm{A}$ loads with $65 \%$ conversion efficiency, and 5\% ripple at an external vibration frequency of $10 \mathrm{~Hz}$ and the maximum output power of $22.5 \mu \mathrm{W}$ [8].

Tao et al. proposed a micro electromagnetic vibration energy harvester with dimension of $4.5 \times 4.5 \times 1 \mathrm{~mm}^{3}$ and total volume of $20 \mathrm{~mm}^{3}$ [9]. This study offers a solution of the micro electromagnetic harvester fully integrated with MEMS fabrication technology, although the produced energy is very limited.

\subsubsection{Electrostatic}

The principle of electrostatic energy harvesting is based on the stucture of variable capacitor to produce charges from a relative motion between two plates [10]. For a parallel plate capacitor with plate area $A$ and plate separation $D$, the capacitance is approximately given by the following equation.

$$
C=\frac{\varepsilon A}{D}=Q P V
$$

Where $\varepsilon$ is the dielectric constant of the insulating material between the plates, $Q$ and $V$ are the charge and the voltage on the capacitor, respectively $[11,12,13]$. The energy stored on the capacitor is

$$
\mathrm{E}=1 / 2 \mathrm{QV}
$$

If the charge is constant, then combining (1) and (2), the energy becomes

$$
\mathrm{E}=\mathrm{Q}^{2} \mathrm{~d} / 2 \mathrm{eA}
$$

While if the voltage is constrained, the energy becomes [14]

$$
\mathrm{E}=\varepsilon A V^{2} / 2 \mathrm{~d}
$$

Sidek et al. designed and simulated an SOI-MEMS electrostatic vibration energy harvester of the size of micron level using the architect module with CoventorWare 2010 [15]. Simulation results show that the harvester is capable of generating power of $5.891 \mu \mathrm{W}$ at the resonant frequency of 2 $\mathrm{kHz}$ that is too high compared to the frequency of ambient vibration.

Sheu et al. developed an in-plane, gap overlap combdrive electrostatic vibration energy harvester with a mass of $4.9 \mathrm{mg}$ to deliver an average output power of $0.0924 \mu \mathrm{W}$ when harvesting $10 \mu \mathrm{m}$ amplitude of motion at $105 \mathrm{~Hz}$ and the size of the harvester was $3000 \mu \mathrm{m} \times 3000 \mu \mathrm{m} \times 500 \mu \mathrm{m}$ [16]. The harvester is implemented by CMOS process on chip. The 
harvester is of small size, and the energy harvested is also at a very low level, targeted only at very low power applications.

\subsubsection{Piezoelectric}

When the Piezoelectric materials are under stress or strain they generate charge. They generally consist of piezoelectric monocrystal, piezoelectric ceramics, piezoelectric polymers, and piezoelectric composites. Piezoelectric ceramic PZT is the most frequently used in present days. Piezoceramics have the mature manufacturing process, cheaper, large electromechanical coupling constants, and high energy conversion rate. As per the different structures, piezoelectric transducers can be separated into unimorph, bimorph, rainbow type, cymbal type, moonie type, stack type, and so forth [17].

Sarker et al. presents a design of battery-less piezoelectric based energy harvesting interface circuits with $300 \mathrm{mV}$ stepup voltage in which DC-DC Step-Up converter technique was used for designing the startup voltage with low voltage energy [18]. They have achieved a boost up of minimum $1.67 \mathrm{~V}$ in there developed circuit for input DC voltage of $300 \mathrm{mV}$.

Sankman et al. presented an industrial application where vibrations at $60 \mathrm{~Hz}$ are commonly found, for example from motors, air ducts and have a high power density of up to 375 $\mu \mathrm{W} / \mathrm{cm}^{3}[19]$.

The three methods of harvesting vibration energy have different advantages and disadvantages in the field of power density, integration with MEMS and IC technology, electrical matching, and so on. But the efficiency of those is related to the vibration frequency due to the mathematical fact that the maximum power output from vibration-based generators is proportional to the cube of the vibration frequency and drops dramatically at low frequencies $(1-100 \mathrm{~Hz})$ [20]. Because the main frequencies in the environment are relatively low, the mechanical energy harvester may need to utilize the upconverter to transform the low frequency into high frequency so as to achieve an increased power output. Among the three vibration energy harvesting methods, the piezoelectric and electrostatic harvesters have the ability to generate voltage ranging from 2 to $10 \mathrm{~V}$ and implemented for small scale energy harvestors, but the electromagnetic harvesters can produce a maximum voltage of $0.1 \mathrm{~V}$ only and implemented for larger devices [21].

\subsection{Light}

Light energy can be harvested from solar and artifiacial light from the ambience. Solar power can be extract as solar thermal power and solar photovoltaic. One is for large scale and another is for WSNs or small/nano scale. Solar photovoltaic is discussed in this paper. According to the photovoltaic principle, solar cells are used to convert sunlight into electrical power directly $[22,23]$. Other lights such as fluorescent and infrared can also be used as the power source for solar cells. According to the materials used, solar cells can be divided into four categories: (i) silicon solar batteries (ii) multicompound solar cells (iii) polymer solar batteries (PPVC) (iv) nanocrystalline solar cells. The silicon solar batteries are most commonly used in today's technology. At present, polycrystalline silicon solar cells for conditions of high-intensity light and outdoor spectrum acquire the largest production and market share, followed by monocrystalline silicon solar cells $[24,25]$.

Brunelli et al. presented a batteryless solar-harvesting circuit which performs maximum-power-point tracking of solar energy collection under nonstationary light conditions, with high efficiency and low energy cost exploiting miniaturized PV modules [26]. The scavenger improves the power consumption of less than $1 \mathrm{~mW}$. Efficiency up to $80 \%$ and ideality diverging by less than $10 \%$ is obtained.

Dondi et al. presented a solar energy harvesting circuit for low-power applications [27]. Under different light intensities and different switching frequencies the performance of two implemented prototypes intended to power a wireless embedded system is evaluated. Measurements showed those higher switching frequencies allow reaching the maximum efficiency of $90 \%$ at higher light intensities, whereas lower operating frequencies perform better under lower irradiance.

Dondi et al. proposed a methodology for optimizing a solar harvester with maximum power point tracking for selfpowered wireless sensor network nodes [28]. The focus was on maximizing the harvester's efficiency in transferring energy from the solar panel to the energy storing device. An analytical model of photovoltaic panel, based on a simplified parameter extraction procedure, was adopted. With discrete components the design procedure helped to reach a maximum efficiency of $85 \%$.

Recently, the scientists are doing work on solar cell which is thinner than spider web. The thickness of this ultrathin solar cell is only 1.9 microns which is equivalent to one tenth of the current thinnest solar battery which is composed of electrodes which are embedded in the plastic tab [29]. The application of this ultrathin, superlight, ultra flexible solar cell in the future includes, portable electronic charging device or for manufacture of electronic textiles. Currently the researchers are increasing the photoelectric conversion efficiency of it. This new solar cell will be place into use within five years.

Also, a new kind of efficient full spectrum solar cell with tandem-type connection based on colloidal quantum dots (CQD) is developed. Its theoretical conversion efficiency is as high as $42 \%$.

\subsection{Thermo}

Thermal energy harvesting can be divided in thermoelectric energy harvesting and pyroelectric energy harvesting.

\subsubsection{Thermoelectric energy}

Thermoelectric energy generators (TEGs) are based on Seebeck effect. TEGs convert temperature differences across dissimilar materials into voltage [30].

$\mathrm{J} \mathrm{Su}$ at el. proposed a micromachined thermoelectric energy harvester with $6 \mu \mathrm{m}$ high polycrystalline silicon germanium (poly-SiGe) thermocouples fabricated on a 6 inch wafer [31].

Yang at el. proposed a micro-thermoelectric generator ( $\mu \mathrm{TEG})$ design based on stacked polysilicon thermocouples, in which the $\mathrm{p}$ - and n-thermolegs of a thermocouple are stacked and insulated [32]. To analyze the optimal thermocouple size by matching their thermal resistance and electrical resistance a thermal model is applied. Analysis showed that the maximum power factor and voltage factor of an optimal thermocouple $100 \mu \mathrm{m} \times 4 \mu \mathrm{m} \times 0.275 / 0.18 \mu \mathrm{m}$ (length $\times$ width $\times$ thickness for $\mathrm{p}$-/n-thermolegs) is $0.0473 \mu \mathrm{W} / \mathrm{cm}^{2} \mathrm{~K}^{2}$ and $3.952 \mathrm{~V} / \mathrm{cm}^{2} \mathrm{~K}$, respectively. The voltage factor is about $142 \%$ of that in co-planar design. Multiple thermocouples can thus be stacked for higher performance.

\subsubsection{Pyroelectric energy}

Pyroelectric energy harvesting is about pyroelectric effect, the spontaneous polarization due to temerature changes in certain anisotropic solids $[33,34]$. A time varing temperature profile is needed for pyroelectric energy harvesting. 
Ravindran et al. concluded that pyroelectric generators (PEGs) present a potential alternative to thermoelectric generators (TEGs), to generate electric power from thermal fields. Pyroelectric generators have a predicted upper limit of $50 \%$ of the Carnot's efficiency, which exceeds that of TEGs [35]. The measured power output of such a harvester is $3 \mu \mathrm{W}$ for a temperature difference of $79.5 \mathrm{~K}$. By improving the harvester design, a power output of approximately $9 \mathrm{~mW}$ is predicted.

Nguyen et al. was concerned with designing, building, and testing a pyroelectric energy converter to directly convert waste heat into electricity [36]. A maximum energy density of $130 \mathrm{~J} / 1$ was achieved at $0.061 \mathrm{~Hz}$ frequency with temperature oscillating between 69.3 and $87.6^{\circ} \mathrm{C}$. Furthermore, a maximum power density of $10.7 \mathrm{~W} / 1$ was obtained at $0.12 \mathrm{~Hz}$ between 70.5 and $85.3^{\circ} \mathrm{C}$. In both cases, the low and high electric fields in the Olsen cycle were 202 and $739 \mathrm{kV} / \mathrm{cm}$.

Pyroelectric energy harvesting produces greater efficiency compared to thermoelectric harvesting. Conversely, thermoelectric energy harvesting provides higher harvested energy levels. Due to various sizes of thermal harvesters, they can be placed on the human body, on structures and equipment [37].

\subsection{Wireless}

Wireless energy harvesting techniques are of two types: RF (Radio Frequency) energy harvesting and resonant energy harvesting.

\subsubsection{RF energy}

RF energy is harvested from the RF emitted by sources such as radio and TV signals, cell phones, WiFi communications and microwaves $[38,39,40]$. An energy harvesting system consists of two main subsystems, one is the receiving antenna, which functions to capture ambient RF energy to power up the integrated embedded system and second subsystem is the rectification circuitry, which converts the input RF power into DC output power efficiently [41].

Sim et al. presented two compact patch antenna designs for a new application outdoor RF energy harvesting in powering a wireless soil sensor network [42]. Zakaria et al. presents an overview and the progress achieved in RF energy harvesting, which involves the integration of antenna with rectifying circuit [43]. Different combinations of antenna and rectifier topologies yield diverse results. They expected to give an indication on the appropriate techniques to develop an efficient RF energy harvesting system. Jabbar at el. presents a modified form of existing CMOS based voltage doubler circuit is presented to achieve $160 \%$ increase in output power over traditional circuits at $0 \mathrm{dBm}$ input power. A schottky diode based RF energy harvesting circuit performance is also studied with practical and simulations results [44].

\subsubsection{Resonant energy}

Resonant energy harvesting is also known as resonant inductive coupling. Tuned circuits are used one at receiver and one at transmitter, due to inductive coupling power is transferred by magnetic fields developed between the circuits [45]. Two types of resonant inductive coupling are: Weak inductive coupling and strong inductive coupling $[46,47]$.

\subsection{Wind}

Wind energy harvesting uses wind turbine generators to convert mechanical energy into electrical energy [48].
Tan et al. presents an optimized wind energy harvesting (WEH) system that uses a specially designed ultra-lowpower-management circuit for sustaining the operation of a wireless sensor node [49]. The proposed power management circuit has two distinct features: 1) an active rectifier using MOSFETs for rectifying the low amplitude ac voltage generated by the wind turbine generator under low wind speed condition efficiently and 2) a dc-dc boost converter with resistor emulation algorithm to perform maximum power point tracking (MPPT) under varying wind-speed conditions. An average electrical power of $7.86 \mathrm{~mW}$ is harvested by the optimized WEH system at an average wind speed of $3.62 \mathrm{~m} / \mathrm{s}$, which is almost four times higher than the conventional energy harvesting method without using the MPPT.

Tan et al. also proposed a satellite-based remote sensing technique which has been widely used in monitoring wildfire spread [50]. An indirect approach in sensing wind speed has been proposed by them as an alternative to the bulky conventional wind anemometer to save cost and space. The experimental results show that the designed WEH system is able to harvest an average electrical power of $7.7 \mathrm{~mW}$ at an average wind speed of $3.62 \mathrm{~m} / \mathrm{s}$ for powering the operation of the wireless sensor node that consumes $3.5 \mathrm{~mW}$ for predicting the wildfire spread.

Cammarano et al. present a novel energy prediction model, named Pro-Energy (PROfile energy prediction model), for multi-source energy harvesting WSNs, which is able to leverage past energy observations to provide accurate estimations of future energy availability [51].

\subsection{Biochemical}

Biochemical energy harvesting involves biological entity. Biological energy is generated due to motion, stretch or matabolic processes in the biological entity that can be converted into electrical energy. Human body includes many bilogical entities. Even though biochemical energy harvesting can be superior to other energy harvesting techniques in terms of continuous power output and biocompatibility, its performance depends on the type and availability of fuel cells [52].

Hansen et al. presented a hybrid energy scavenging device for potential in vivo applications [53]. The hybrid device consists of a piezoelectric poly(vinylidene fluoride) nanofiber nanogenerator for harvesting mechanical energy, such as from breathing or from the beat of a heart, and a flexible enzymatic biofuel cell for harvesting the biochemical (glucose $/ \mathrm{O}_{2}$ ) energy in biofluid, which are two types of energy. The two energy harvesting approaches can work simultaneously or individually, thereby boosting output and lifetime.

\subsection{Acoustic}

Acoustic energy harvesting performs conversion of acoustic energy into electrical energy by using piezoelectric transduction [54]. Piezoelectric and electromagnetic based acoustic energy harvesters are developed [55].

\section{CONVERTORS}

There are a number of different circuit topologies that allow the conversion of electrical energy.

- DC-DC converters- Step up(Buck), Step Down (Boost), Step-up/step-down(buck-boost), Full bridge Converters

- DC-AC inverters 
- $\quad$ AC-DC rectifiers- both controlled DC output and uncontrolled DC Output

Dahiya et al. presented the design of wireless sensor network (WSN) in energy conversion module based on multiplier circuit. This energy conversion module can function as an AC to $\mathrm{DC}$ converter that not only rectifies the input $\mathrm{AC}$ signal but also elevates the DC voltage level [56]. Two types of multiplier circuits namely single stage multiplier circuits and multistage multiplier circuits to design the wireless sensor networks are used. Mathematical analysis also presented for the single and multistage multiplier circuits. Efficiency and multistage voltage output are the two parameters use to analysis the performance of the designed WSN based on multiplier circuits. Simulation results show the relationship between output voltage and RF power of the WSN system with different level of multipliers stage. Results shows that the efficiency analysis of the WSN with the different multiplier stages. Graphical results show that the efficiency of the system goes on increases with the increase in the multipliers stages. Results show the effectiveness of the designed system.

Rao et al. presents an efficient ac-to-dc power converter that avoids the bridge rectification and directly converts the low ac input voltage to the required high dc output voltage at a higher efficiency [57]. The proposed converter consists of a boost converter in parallel with a buck-boost converter, which are operated in the positive half cycle and negative half cycle, respectively. Detailed analysis of the converter is carried out to obtain relations between the power, circuit parameters, and duty cycle of the converter.

Anyway, the universal means of converting energy from sources with differing output characteristics is an open research problem with different storage devices.

\section{STORAGE}

The energy storage devices considered include rechargeable batteries and supercapacitors. Supercapacitor and rechargeable batteries are common choice of energy storage, are made up of several chemical compositions. Some common rechargeable storage technologies are Nickel Metal Hydride (NiMH), Nickel Cadmium (NiCd), Lithium Ion (Li-ion) and Sealed Lead Acid (SLA). These technologies can be characterized along several axes energy density, power, storage efficiency, discharge rate and number of deep recharge cycles [58]. Table 2 shows the typical values of output voltage, energy density and recharge cycles across different storage technologies.

Table 2. Comparison of storage Technology

\begin{tabular}{|c|c|c|c|}
\hline $\begin{array}{c}\text { Storage } \\
\text { Technology }\end{array}$ & $\begin{array}{c}\text { Output } \\
\text { Voltage(volt) }\end{array}$ & $\begin{array}{c}\text { Energy } \\
\text { Density(MJ/kg) }\end{array}$ & $\begin{array}{c}\text { Recharge } \\
\text { Cycles }\end{array}$ \\
\hline NiMH & 1.2 & $0.11-0.29$ & 1000 \\
\hline $\begin{array}{c}\text { NI- } \\
\text { cadmium }\end{array}$ & 1.2 & $0.14-0.22$ & 1500 \\
\hline Li-ion & 3.6 & 0.58 & 1200 \\
\hline $\begin{array}{c}\text { Sealed } \\
\text { Lead acid }\end{array}$ & .6 & $0.11-0.14$ & $500-800$ \\
\hline $\begin{array}{c}\text { Super } \\
\text { Capacitor }\end{array}$ & $>4$ & $5-8$ & $\begin{array}{c}>1 \\
\text { million }\end{array}$ \\
\hline
\end{tabular}

Table 2 shows that lithium ion batteries have higher output voltage, energy density and recharge cycle among all batteries. But the supercapacitor has the highest output paramerers. Though NiMH has better energy density than $\mathrm{NiCd}$, but $\mathrm{NiCd}$ has high number of deep recharge cycles. Sealed Lead Acid has the lowest values for energy density and number of cycles and hence is the least effective storage technology. From the perspective of using batteries for storing harvested energy, the supercapacitor storage technology appears to be the best. Advantage of supercapacitor is that it does not suffer from memory effect-loss of energy capacity due to repeated shallow recharge. Another popular battery technology is Nickel-Metal Hydride. NiMH batteries have reasonably high energy and recharge cycles. An advantage of $\mathrm{NiMH}$ batteries is that they can be trickle charged, i.e., directly connected to an energy source for charging. Though $\mathrm{NiMH}$ batteries suffer from memory effect, the effect is reversible by conditioning fully discharging the battery after charging it. Alternatively, super-capacitors can be used instead of or along with rechargeable batteries as storage components. Like batteries, super-capacitors also store charge, but they self-discharge at a higher rate than batteries. Theoretically, super-capacitors have infinite recharge cycles, and therefore have no limit to the number of times they can undergo deep recharge.

Guan et al. compares several energy storage devices including conventional capacitors, rechargeable batteries, and supercapacitors in piezoelectric energy harvesting [59]. Their charge/discharge efficiency, adaptability, lifetime, and selfdischarge are investigated and discussed. A quick test method is proposed to experimentally study the charge/discharge efficiency of the energy storage devices. The results show that the supercapacitors are suitable and more attractive than the rechargeable batteries as energy storage devices in energy harvesting for wireless sensor networks.

\section{CONCLUSION}

Energy harvesting or scavenging from the ambience is one of the better options to improve the life-time of wireless sensor networks by replacing batteries. In many cases, the harvested or scavenged energy is not enough to power the sensor nodes. Power converters are used to convert the available power to recharge the batteries or to be stored in storage devices. Due to these limitations of low harvested energy from the environment, researches are working to develop a novel power converter and energy storage system used along with energy harvestor or scavenger system to provide an appropriate solution to the problem of powering nodes in wireless sensor networks for different application scenarios. Many energy sources have no commercial solution in the market and needs extensive research. Anyway energy harvester, power converters and storage devices collectively remain an interesting research topic to provide one of the best solutions to power sensor nodes in the field of wireless sensor networks.

\section{REFERENCES}

[1] Tentzeris, M. M. Georgiadis, A. and Roselli, L. 2014. Energy Harvesting and Scavenging, IEEE Guest Editor Proceedings of the IEEE, vol. 102, no. 11, pp.16441648.

[2] Knight, C. Davidson, J. and Behrens, S. 2008. Energy Options for Wireless Sensor Nodes, Sensors, vol. 8, no. 12, pp.8037-8066.

[3] Sankman, J. and Ma, D. 2015. A 12- $\mu \mathrm{W}$ to 1.1-mW AIM Piezoelectric Energy Harvester for Time-Varying Vibrations With 450-nA $\mathrm{I}_{\mathrm{Q}}$, IEEE Transactions on Power Electronics, vol. 30, no. 2, pp.632-343.

[4] Harne, R. L. and Wang, K. W. 2013. A review of the recent research on vibration energy harvesting via bistasble systems, Smart Materials and Structures, vol. 22, no. 2, pp.023001. 
[5] Stephen, N. G. 2006. On Energy Harvesting from Ambient Vibration, Journal of Sound and Vibration, vol. 293, no. 1-2, pp.409-425.

[6] Shearwood, C. and Yates, R. B. 1997. Development of an Electromagnetic Microgenerator, Electronics Letters, vol. 33, pp.1883-1884.

[7] Miki, S. Fujita, T. Kotoge T. et al., Electromagnetic energy harvester by using buried $\mathrm{NdFeB}$, in Proc. IEEE 25th International Conference on MEMS, pp.1221-1224.

[8] Rahimi, A. Zorlu, O. Muhtaroglu, A. and Kulah, H. 2011. A vibration-based electromagnetic energy harvester system with highly efficient interface electronics, in Proc. 16 ${ }^{\text {th }}$ International Solid-State Sensors, Actuators and Microsystems Conference, Beijing, pp.2650-2653.

[9] Tao, K. Ding, G. Wang, P. Yang, Z. and Wang, Y. 2012. Fully integrated micro electromagnetic vibration energy harvesters with micro-patterning of bondedmagnets, in Proc. IEEE 25th International Conference on MEMS, Paris, pp.1237-1240.

[10] Moghe, R. Yang, Y. Lambert, F. and Divan, D. 2009. A scoping study of electric and magnetic field energy harvesting for wireless sensor networks in power system applications, in Proc. IEEE ECCE, San Jose, CA, pp.3550-557.

[11] Roundy, S. Wright, P. K. and Rabaey, J. 2003. A Study of Low Level Vibrations as a Power Source for Wireless Sensor Nodes, Computer Communications, vol. 26, no. 11, pp.1131-1144.

[12] Kiziroglou, M. E. He, C. and Yeatman, E. M. 2010. Flexible substrate electrostatic energy harvester, IEEE Electronics Letters, vol. 46, no. 2, pp.166-167.

[13] He, C. Arora, A. Kiziroglou, M. E. Yates, D. C. Hare, D. O. and Yeatman, E. M. 2009. MEMS energy harvesting powered wireless biometric sensor, in Proc. BSN, Berkeley, CA, pp.207-212.

[14] Gilbertand, J. M. and Balouchi, F. 2008. Comparison of Energy Harvesting Systems for Wireless Sensor Networks," International Journal of Automation and Computing, vol. 05, no. 4, pp.334-347.

[15] Sidek, O. Khalid, M. A. Ishak, M. Z. and Miskam, M. A. 2011. Design and simulation of SOI-MEMS electrostatic vibration energy harvester for micro power generation, in Proc. $1^{\text {st }}$ InECCE, Pahang, pp.207-212.

[16] Sheu, G. J. Yang, S. M. and Lee, T. 2011. Development of a low frequency electrostatic comb-drive energy harvester compatible to SoC design by CMOS process, Sensors and Actuators, A: Physical, vol. 167, no. 1, pp.70-76.

[17] Torres, E. O. 2010. An Electrostatic CMOS/BiCMOS Li Ion Vibration-based Harvester- Charger IC, PhD thesis, Georgia Institute of Technology.

[18] Sarker, M. R. Sawal, H. Md. A. Othman, M. and Islam, S. 2013. Designing a Battery-Less Piezoelectric based Energy Harvesting Interface Circuit with 300 mV Startup Voltage, in Journal of Physics: Conference Series 431 3rd ISESCO IWCN, Malaysia, pp.65-73.

[19] Sankman, J. Ma, D. 2015. A 12- $\mu \mathrm{W}$ to $1.1-\mathrm{mW}$ Aim Piezoelectric Energy Harvester for Time-Varying
Vibrations With 450-nA, IEEE Transactions on Power Electronics, vol. 30, vol. 2, pp.632-643.

[20] Zorlu, O. Topal, E. T. and Kulah, H. 2011. A vibrationbased electromagnetic energy harvester using mechanical frequency up-conversion method, IEEE Sensors Journal, vol. 11 , no. 2 , pp.481-488.

[21] Sari, I. Balkan, T. and Kulah, H. 2010. An electromagnetic micro power generator for lowfrequency environmental vibrations based on the frequency up conversion technique, IEEE Journal of Microelectromechanical Systems, vol. 19, no. 1, pp.1427.

[22] Tabbakh, S. R. K. Maarefdoust, R. Kyun, N. C. and Ali, B.Mohd. 2010. Environmental taxonomy of power scavenging techniques for autonomous self poweredwireless sensors, in Proc. APCCAS, Kuala Lumpur, pp.1031-1034.

[23] Roundy, S. Steingart, D. Frechette, Wright, L. P. and Rabaey, J. 2004. Power Sources for Wireless Sensor Networks, Lecture Notes in Computer Science, Springer.

[24] Vullers, R. J. M. Schaijk, R. van. Doms, I. Van Hoof, C. and Mertens, R. 2009. Micropower energy harvesting, Solid-State Electronics, vol. 53, no. 7, pp.684-693.

[25] Brunelli, D. Benini, L. Moser, C. and Thiele, L. 2008. An efficient solar energy harvester for wireless sensor nodes, in Proc. DATE, Munich, pp.104-109.

[26] Brunelli, D. Moser, C. Thiele, L. and Benini, L. 2009. Design of a Solar-Harvesting Circuit for Batteryless Embedded Systems, IEEE Transaction on circuits and systems, vol. 56, no. 11, pp.2519-2528.

[27] Dondi, D. Bertacchini, A. Larcher, L. Pavan, P. Brunelli, D. and Benini, L. 2008. A solar energy harvesting circuit for low power applications, in Proc. ICSET, Singapore, pp.945-949.

[28] Dondi, D. Bertacchini, A. Brunelli, D. Larcher, L. and Benini, L. 2008. Modeling and Optimization of a Solar Energy Harvester System for Self-Powered Wireless Sensor Networks, IEEE Transactions on industrial electronics, vol. 55, no. 7, pp.2759-2766.

[29] Dondi, D. Brunelli, D. Benini, L. Pavan, P. Bertacchini, A. and Larcher, L. 2007. Photovoltaic cell modeling for solar energy powered sensor networks, in Proc. 2nd IEEE IWASI, Bari, pp.1-6.

[30] Hudak, N. S. and Amatucci, G. G. 2008. Small-scale energy harvesting through thermoelectric, vibration, and radio frequency power conversion, Journal of Applied Physics, vol. 103, no. 10, pp.101301.

[31] Su, J. Leonov, V. Goedbloed, M. Andel, Y. Nooijer, M. C. de Elfrink, R. Wang, Z. and Vullers, R. J. M. 2010. A batch process micromachined thermoelectric energy harvester: fabrication and characterization, Journal of Micromechanics and Microengineering, vol. 20, no. 10, pp.104005.

[32] Yang, S. M. Lee, T. and Cong, M. 2010. Design and verification of a thermoelectric energy harvester with stacked polysilicon thermocouples by CMOS process, Sensors and Actuators A: Physical, vol. 157, no. 2, pp.258-266. 
[33] Lu, X. and Yang, S. H. 2010. Thermal energy harvesting for WSNs," in Proc. IEEE SMC, Istanbul, pp. 30453052.

[34] Abbaspour, R. 2010. A practical approach to powering wireless sensor nodes by harvesting energy from heat ow in room temperature, in Proc. IEEE ICUMT, Moscow, pp. $178-181$.

[35] Ravindran, S. K. T. Huesgen, T. Kroener, M. Woias, P. 2011. A self-sustaining pyroelectric energy harvester utilizing spatial thermal gradients, in Proc. 16th International Solid-State Sensors, Actuators and Microsystems Conference (TRANSDUCERS), Beijing, pp.657-660.

[36] Nguyen, H. Navid, A. and Pilon, L. 2010. Pyroelectric energy converter using co-polymer $\mathrm{P}(\mathrm{VDF}-\mathrm{TrFE})$ and Olsen cycle for waste heat energy harvesting, Applied Thermal Engineering, vol. 30, no. 14-15, pp. 2127-2137.

[37] Moghe, R. Yang, Y. Lambert, F. and Divan, D. 2009. A scoping study of electric and magnetic field energy harvesting for wireless sensor networks in power system applications," in Proc. IEEE ECCE, San Jose, CA, pp. 3550-3557.

[38] Sim, Z. W. Shuttleworth, R. and Grieve, B. 2009. Investigation of PCB Microstrip Patch Receiving Antenna for Outdoor RF Energy Harvesting in Wireless Sensor Networks, in Proc. Antennas \& Propogation Conference, Loughborough, pp. 129-132.

[39] Patel, A. C. Vaghela, M. P. Bajwa, H. and Patra, P. K. 2009. Power Harvesting for Low Power Wireless Sensor Network, in Proc. Antennas \& Propogation Conference, Loughborough, pp. 633-636.

[40] Thomas, J. P. Qidwai, M. A. and Kellogg, J. C. 2006. Energy scavenging for small-scale unmanned systems, Journal of Power Sources, vol. 159, no. 2, pp.1494-1509.

[41] Arrawatia, M. Baghini, M. S. and Kumar, G. 2010. RF Energy Harvesting System at 2.67 and $5.8 \mathrm{GHz}$, in Proc. APMC, Yokohama, pp. 900-903.

[42] Sim, Z. W. Shuttleworth, R. Alexander, M. J. and Grieve, B. D. 2010. Compact patch antenna design for outdoor RF energy harvesting in wireless sensor networks, Progress in Electromagnetics Research, vol. 105, pp.273-294.

[43] Zakaria, Z. Zainuddin, N. A. Husain, M. N. Aziz, M. Z. A. A. Mutalib, M. A. and Othman, A. R. 2013. Current Developments of RF Energy Harvesting System for Wireless Sensor Networks, Advances in information Sciences and Service Sciences(AISS), vol. 5, pp. 328338.

[44] Jabbar, H. Song, Y. S. and Jeong, T. T. 2010. RF energy harvesting system and circuits for charging of mobile devices, Consumer Electronics, IEEE Transactions on, vol.56, no. 1, pp.247-253.

[45] Mandal, S. Turicchia, L. and Sarpeshkar, R. 2010. A low-power, battery-free tag for body sensor networks, IEEE Pervasive Computing, vol. 9, no. 1, pp.71-77.

[46] Reinisch, H. Gruber, S. Unterassinger, H. Wiessecker, M. Hofer, G. Pribyl, W. and Holweg, G. 201. An electromagnetic energy harvesting system with $190 \mathrm{nW}$ idle mode power consumption for a BAW based wireless sensor node, IEEE Journal of Solid-State Circuits, vol. 46, no. 7, pp.1728-1741.

[47] Heer, R. Wissenwasser, J. Milnera, M. Farmer, L. Hopfner, C. and Vellekoop, M. 2010. Wireless powered electronic sensors for biological applications, in Proc. IEEE EMBC, Buenos Aires, pp.700-703.

[48] Fei, F. Mai, J. D. and Li, W. J. 2012. A wind-flutter energy converter for powering wireless sensors, Sensors and Actuators A: Physical, vol. 173, no. 1, pp.163-171.

[49] Tan Y. K. and Panda, S. K. 2011. Optimized Wind Energy Harvesting System Using Resistance Emulator and Active Rectifier for Wireless Sensor Nodes, IEEE Transactions on Power Electronics, vol. 26, no. 1, pp.3850 .

[50] Tan Y. K. and Panda, S. K. 2011. Self-autonomous wireless sensor nodes with wind energy harvesting for remote sensing of wind-driven wildfire spread, IEEE Transactions on Instrumentation and Measurement, vol. 60, no. 4, pp.1367-1377.

[51] Cammarano, A. Petrioli, C. and Spenza, D. 2012. ProEnergy: A novel energy prediction model for solar and wind energy-harvesting wireless sensor networks, in Proc. IEEE 9th International Conference on Mobile Adhoc and Sensor Systems, Las Vegas, NV, pp.75-83.

[52] Davis F. and Higson, S. P. J. 2007. Biofuel cells-recent advances and applications, Biosensors and Bioelectronics, vol. 22, no.7, pp.1224-1235.

[53] Hansen, B. J. Liu, Y. Yang, R. and Wang, Z. L. 2010 Hybrid Nanogenerator for Concurrently Harvesting Biomechanical and Biochemical Energy, ACS Nano, vol. 4, no. 7, pp.3647-3652.

[54] Liu, F. Phipps, A. Horowitz, S. Ngo, K. Cattafesta, L. Nishida, T. and Sheplak, M. 2008. Acoustic energy harvesting using an electromechanical Helmholtz resonator, Journal of the Acoustical Society of America, vol. 123, no. 4, pp.1983-1990.

[55] Khan F. U. and Izhar. 2015. State of the art in acoustic energy harvesting, Journal of Micromechanics and Microengineering, vol. 25, no. 2, pp.023001

[56] Dahiya, R. Arora A. K. and Singh, V. R. 2014. Design of Wireless Sensor Networks (WSN) in Energy Conversion Module Based On Multiplier Circuits, International Journal of Engineering and Innovative Technology (IJEIT), vol. 3, no. 12, pp.127-131

[57] Rao S.V. and Balaji, A. 2013. A Novel AC-DC Step-Up Converter For Energy Harvesting, International Journal of Engineering Research and Development, vol. 8, no. 1, pp.60-72.

[58] Sudevalayam, S. and Kulkarni, P. 2010. Energy Harvesting Sensor Nodes: Survey and Implications, IEEE Communications Surveys \& Tutorials, vol. 13, no. 3 , pp.443-461.

[59] Guan M. J. and Liao, W. H. 2006. On the energy storage devices in piezoelectric energy harvesting, in Proc. SPIE 6169, Smart Structures and Materials, San Diego, CA, pp. 58-64. 